\title{
A new method for supply chain coordination with credit option contract and customers' backordered demand
}

\author{
Reza Hasani, Hassan Jafarzadeh* and Farid Khoshalhan
}

Department of Industrial Engineering, K. N. Toosi University of Technology, Tehran, Iran

\section{H R O N I C L E}

Article history:

Received June 10,2013

Received in revised format

25 August 2013

Accepted September 22013

Available online

September 82013

\section{Keywords:}

Supply chain coordination

Coordination mechanisms

Credit option contract

Delay in payment

Channel coordination

Backorder \begin{abstract}
A B S T R A C T
This paper studies the issue of channel coordination for a decentralized supply chain consisting of one vendor and one buyer in multi-period setting. Considering the allowance of the backorder at the buyer side distinguishes this work in the literature. The credit option contract as an incentive scheme is pursued to encourage the buyer to participate in the coordination model. Order quantity, credit time and backordered demand in each period as decision variables are determined jointly in order to encourage the chain's member to participate in the coordinating contract. The proposed model shows that the credit option contract for the case of backorder allowance is able to realize the channel coordination in the studied supply chain. A wide range of numerical examples are studied to analyze the sensitivity of the contract efficiency to the inventory system's parameters such as order cost, holding cost and shortage cost.
\end{abstract}

(C) 2013 Growing Science Ltd. All rights reserved.

\section{Introduction}

A supply chain consists of suppliers, distributors, retailers and customers, cooperating to satisfy customers' demand. In general, a good planning, scheduling and control policy must be beneficial for the whole supply chain and for each participating business unit. In practice, each company attempts to optimize its own business unit subject to some certain constraints (e.g., contractual obligations) with little attention to the remaining stages of the supply chain. Although such decentralized policies can be independently optimal, but the profit in this policy can be much lower than the maximum profit the system could make under centralized policies. As a common case, the buyer determines optimal order size known as $Q$. It is notable that the optimal production batch size for a producer (an upstream member of supply chain) is different from $Q$ (usually larger). Any deviation from optimal order size and optimal production batch size increases the members operational cost, and consequently decreases whole chains profitability.

* Corresponding author. Tel: +989395085145

E-mail addresses: hjafarzadeh@mail.kntu.ac.ir (H. Jafarzadeh)

(C) 2013 Growing Science Ltd. All rights reserved.

doi: $10.5267 /$ j.uscm.2013.09.002 
In such circumstances, a coordination policy may be necessary to motivate the members to achieve coordination (Kanda \& Deshmukh, 2009). According to Malone and Crowston (1994), coordination can be defined as "an act of working together and managing dependencies between different entities". Hill and Omar (2006) defined supply chain coordination from a joint decision-making point of view as follow: "Coordination can be achieved when the supply chain members jointly minimize the operating costs and share the benefits after jointly planning the production and scheduling policies".

Supply chain contracts are useful mechanisms to coordinate decentralized supply chains. In the contract the parameters are set (e.g. order size, price, credit time) such to coordinate the supply chain members and also to optimize the performance of the supply chain (Cachon, 2004). Kanda and Deshmukh (2009) stated that supply chain members are responsible to coordinate by applying contracts for better management of vendor-buyer relationship and risk management. Moreover, they classified contracts under supply chain coordination mechanisms.

Cachon (2004) made a complete review on supply chain coordination by contracts. Quantity discount, the broadly discussed kind of contracts, return policies and revenue sharing are commonly investigated in the literature. This mechanism has primarily been implemented to coordinate order quantity in a supply chain modelled in deterministic environment. Return policies and revenue sharing contracts are also applicable in a single period with stochastic demand. Quantity discount, return policies and revenue sharing contracts encourage downstream members of the chain to order more than local decentralized optimum order quantity to increase whole chain profitability. In some applied contracts channel coordination is achievable, which means by applying recommended mechanisms a coordinated decentralized supply chain works like a centralized supply chain. Credit option contract have been investigated less than other models. Using a credit option contract, the downstream party can utilize the benefit of delayed payment in buying goods, subject to a commitment to undertake coordinated decision making. Recently credit option contract has been applied by Chaharsooghi and Heydari (2010) to coordinate order quantity and reorder point of a supply chain.

Harris (1913) introduced economic order quantity (EOQ) model. His model has been extended under various circumstances. One of the most important extensions of EOQ model is to consider shortage as part of the proposed model. When demand signal is received and there are not enough inventories to satisfy the demand, it is backordered and fulfilled in the next period. Although considering the allowed shortage is common in the inventory management literature, fewer researches have been devoted to investigate inventory models when shortage is allowed in the coordination literature (Wang, 2004; Zhou, 2009; Halati \& He, 2010). Sarmah et al. (2007, 2008) and Heydari et al. (2010) recently developed a coordination mechanism using credit option contract in a 2- echelon supply chain. Nevertheless, the former case considered shortage allowance in the inventory model.

In this paper, a coordination model for joint determination of order quantity has been developed. Credit option contact which is the less investigated kind of contracts in the literature is considered as coordination mechanism among members. In order to make the model more realistic, it has been assumed that unsatisfied demand of the customers in a period is backordered and satisfied in the next period. It is illustrated that coordination among supply chain members' in order to determine the size of lot size and to increase chain's profitability. Described model considers a two-echelon supply chain consisting of one buyer and one supplier where customer demand is assumed to be certain and determined. It is also assumed that the buyer's inventory system behaves like a classic EOQ model in which shortage is allowed. Order quantity, backordered demand and credit times in each period are decision variables. A coordination model based on credit option is developed in the third section and the forth section presents numerical examples. The results of numerical experiments show that channel coordination is achievable by utilizing the proposed model. In channel coordination, members' profit after coordination is at least equal to their profit before coordination and whole 
chain's performance is similar a centralized chain. Also it is deducible that, in an inventory system, the minimum credit time to coordinate the chain will be significantly increased when shortage is allowed.

\section{Literature review}

Coordination is a key concept in supply chains and there are many definitions of supply chain management where coordination plays an important role. The most important coordination models introduced in the literature are quantity discount, return policies, revenue sharing, credit option (delay in payments), and quantity flexibility contracts. These models have been applied to coordinate the order quantities. Quantity discount contract has been applied in both deterministic and stochastic environments; this contract is the broadly investigated coordination model. Credit option contract only has been implemented for the deterministic environments, and is the less investigated. Return policies, revenue sharing; buyback and flexibility contracts are mainly applicable in coordinating single period and uncertain demand inventory systems (newsvendor problems).

As mentioned above credit option contracts have been investigated less than other coordination mechanisms. One of the fundamental assumptions of the traditional inventory models is to pay the cost items at the delivery time by the buyer. But in the real world, the supplier can give buyer a trade credit period for paying the purchasing cost. This credit period can work as an incentive to encourage the buyer to increase his order size.

Coordinating supply chain members in their inventory decision problems is one of the most popular issues in the literature. Sarmah (2006) noted that integrated inventory models are the origin of supply chain coordination study from the operation management perspective. These models study supply chain's performance before and after order quantity coordination. Sarmah $(2007,2008)$ also reviewed supply chain coordination (SCC) literature and classified SCC models as follows,

(1) Vendor /manufacture's perspective coordination models, which maximize the supplier's yearly net profit (YNP) and giving incentive to buyer to cooperate in contract.

(2) Joint buyer and vendor perspective coordination models, which minimize the total system cost with respect to coordinated lot size or order quantity.

(3) Buyer/ vendor coordination models under game theoretic framework: in this models buyer/ vendor coordination models are considered as a non-cooperative game or a cooperative game models.

(4) Single vendor and multiple buyers' coordination models.

In this paper, we consider a single buyer and single vendor coordination model by considering EOQ assumptions for the buyer, which is collected in the first category. With the assumption that vendor has full information about the buyer's cost structure, the first category considers the problem from vendor's/supplier's view point where the aim is to maximize the vendor's profit function.

In the literature, various models have been developed. In Abad and Jaggi's (2003), model the unit price and the length of the credit period offered by the seller to the buyer are decision variables. Both unit price and credit period influence the final demand for the product. Sheen and Tsao (2007) considered vendor-buyer channel coordination and solved the problem of determining vendor's credit period, the buyer's retail price and order quantity while maximizing profits. In their model freight carrier gives price freight-transport discounts that are related to the amount of cargo transported. Jaber and Osman (2006), Proposed a model to coordinate order Quantity in which delay in payment is allowed and is variable. Kin Chan et al. (2010) presented a coordination model by synchronizing ordering and production cycle with delayed payment. They also adopt varying delayed payment period so as to guarantee that each buyer will have the same cost as in independent optimization. for the first time in the literature Chaharsooghi and Heydari (2010) proposed a SCC model for 
simultaneous coordination of order quantity and reorder point and concluded that coordination of the reorder point with order quantity can increase chain profitability. Furthermore they modelled lead time and demand uncertainty and achieved coordination using a credit option contract. Sarmah et al. (2007) developed a vendor/a buyer coordination mechanism through credit option and shared surplus profit of members after coordination. Their models have been developed under 2 cases: members without target profit and members with individual target profit. This problem has been modelled in the deterministic environment. In addition, Sarmah et al. (2008) extended their previous study to coordinate a single vendor and multi buyer supply chain.

Over the past decades, many deterministic inventory models have been developed to extend the EOQ models by adding different considerations, such as backordered demand, perishable or deteriorating items, stock or price dependent demand. Considering the allowed backorder is a common assumption in inventory management literature and there some other models for deterministic EOQ problem by considering backorders (Pentico \& Drake, 2011). Although, there have been various efforts to develop coordination mechanisms in deterministic inventory models, almost in all reviewed papers shortage is not allowed for vendor and buyer.

In this paper, we consider a vendor/buyer supply chain with the assumption of considering EOQ where backorder is allowed. Allowing backorder relaxes one of the unrealistic assumptions of classic EOQ model and consequently makes the considered model more realistic. Model is coordinated through a credit option mechanism and surplus profit after coordination is shared between two parties.

\section{Model Description}

\subsection{Assumptions}

The following assumptions have been considered:

a) Supply chain is 2-echelon with single buyer and single vendor

b) Replenishment for buyer is instantaneous

c) Yearly Demand rate is fixed and deterministic

d) Members have complete information about each other's cost structure.

e) A single item is considered

f) All parameters are deterministic

g)Unsatisfied demand is backordered for the next period

\subsection{Notations}

$D: \quad$ Yearly Demand

Q: $\quad$ Order Quantity (Decision variable)

$t: \quad$ Credit time (Decision variable)

$C$ : $\quad$ Manufacturing cost per unit

$P: \quad$ Sell price per unit

$R: \quad$ Retail price per unit

$h$ : $\quad$ Holding cost per unit 
A: $\quad$ Ordering cost for buyer/ setup cost for vendor

$S: \quad$ Backordered demand in each period (Decision variable)

$\hat{\pi}$ : $\quad$ Time dependent shortage cost

$Y N P$ : Yearly net profit

TC: $\quad$ Total cost in each period

Indices: " $b$ " means buyer; " $m$ " states for manufacturer/vendor/supplier; " $o p$ " is for optimum quantity of variable; "co" is coordinate quantity of variable.

\subsection{Model}

The proposed model of this paper is a vendor/manufacture's perspective coordination model, which calculates coordinated order quantity by maximizing vendor's $Y N P$ and sharing additional profit with buyer. In this model, two parties decide to increase order quantity. Accordingly, YNP for both vendor and total cost for buyer increases. Vendor offers a persuading credit time to convince the buyer collaborating in the contract. By considering $\mathrm{Q}$ as order size total cost of the buyer is:

$T C_{b}=\frac{D}{Q} A_{b}+\frac{1}{2 Q} h_{b}(Q-s)^{2}+\frac{1}{2 Q}\left(\hat{\pi} . s^{2}\right)$

If $\hat{\pi} \neq 0$, the optimal order quantity and the optimal backorder in the non-coordinated system can be calculated as:

$Q^{d}=\sqrt{\left(\frac{\hat{\pi}+h_{b}}{\hat{\pi}}\right)} \cdot \sqrt{\frac{2 A_{b} D}{h_{b}}}$,

$s^{d}=\frac{\sqrt{2 D A_{b} h_{b} \cdot\left(1+\frac{h_{b}}{\hat{\pi}}\right)}}{\left[\hat{\pi}+h_{b}\right]}$,

where the buyer orders at his optimum order level, yearly net profit of the manufacturer/vendor, $\left(Y N P_{m}\right)$, will be (which is not optimum) as follows,

$Y N P_{m}^{d}=(P-c) D-\frac{D A_{m}}{Q}$

According to a credit option contract, the buyer and vendor adopt a larger order quantity than $Q^{d}$.When the buyer orders larger amount of items, his total cost increase and vendor compensates additional cost via a credit option mechanism. The following cost will be added to buyer's total cost:

$Z=T C_{b}\left(Q^{c o}, s^{c o}\right)-T C_{b}\left(Q^{d}, s^{d}\right)$

Consequently, vendor's YNP after compensating buyer's additional cost is as follows,

$Y N P_{m}=(P-c) D-\frac{D \cdot A_{m}}{Q}-\left(\frac{D \cdot A_{b}}{Q}+\frac{1}{2 Q} h_{b} \cdot(Q-s)^{2}+\frac{1}{2 Q} \hat{\pi} s^{2}-T C_{b}\left(Q^{d}, s^{d}\right)\right)$

For a given set of parameters, the last term is constant and can be calculated by using Eqs. (1-3).

Differentiating Eq. (6) respect to $Q$ and $s$ and doing some calculations gives optimal $Q$ and $s$ which maximizes $Y N P_{\mathrm{m}}$ : 


$$
\begin{aligned}
& \left\{\begin{array}{l}
\frac{\partial Y N P_{m}}{\partial Q}=0 \\
\frac{\partial Y N P_{m}}{\partial s}=0
\end{array}\right. \\
& Q^{c o}=\sqrt{\frac{2 D\left(h_{b}+\hat{\pi}\right) \cdot\left(A_{b}+A_{m}\right)}{\left(\hat{\pi} \cdot h_{b}\right)}}, \\
& S^{c o}=\frac{\sqrt{2 D h_{b} \cdot\left(A_{b}+A_{m}\right)}}{\hat{\pi} \cdot\left(\hat{\pi}+h_{b}\right)} .
\end{aligned}
$$

In the coordinated setting, order quantity $\left(Q^{c o}\right)$ of the buyer increases. Minimum required time, which compensates the increase in buyers cost is as follows,

$$
\left(\frac{D \cdot A_{b}}{Q^{c o}}+\frac{1}{2 Q^{c o}} h_{b} \cdot\left(Q^{c o}-s^{c o}\right)^{2}+\frac{1}{2 Q^{c o}} \hat{\pi} s^{c o^{2}}\right)-\left(\frac{D \cdot A_{b}}{Q^{d}}+\frac{1}{2 Q^{d}} h_{b} \cdot\left(Q^{d}-s^{d}\right)^{2}+\frac{1}{2 Q^{d}} \hat{\pi} s^{d^{2}}\right)=D t_{\min } h_{b},
$$

where $t_{\max }$ is the maximum credit time that the vendor can offer to the buyer without exceeding his cost with respect to a non-coordinated setting.

$$
\begin{aligned}
& \frac{\mathrm{DA}_{\mathrm{m}}}{\mathrm{Q}^{\mathrm{d}}}-\frac{\mathrm{DA}_{\mathrm{m}}}{\mathrm{Q}^{c o}}=\mathrm{D} \cdot t_{\text {max }} \cdot h_{m} \\
& t_{\text {max }}=\frac{\frac{\mathrm{DA}_{\mathrm{m}}}{\mathrm{Q}^{\mathrm{d}}-\frac{\mathrm{DA}_{\mathrm{m}}}{\mathrm{Q}^{c o}}}}{\mathrm{D} \cdot h_{m}}=\frac{\mathrm{A}_{\mathrm{m}}}{h_{m}}\left(\frac{1}{\mathrm{Q}^{\mathrm{d}}}-\frac{1}{\mathrm{Q}^{c o}}\right) .
\end{aligned}
$$

Accordingly, feasible credit time range is:

$$
\begin{aligned}
& \frac{\left(\frac{D . A_{b}}{Q^{c o}}+\frac{1}{2 Q^{c o}} h_{b} \cdot\left(Q^{c o}-s^{c o}\right)^{2}+\frac{1}{2 Q^{c o}} \hat{\pi} s^{c o}\right)}{\text { D. } \mathrm{h}_{\mathrm{b}}}-\frac{\left(\frac{D \cdot A_{b}}{Q^{d}}+\frac{1}{2 Q^{d}} h_{b} \cdot\left(Q^{d}-s^{d}\right)^{2}+\frac{1}{2 Q^{d}} \hat{\pi} s^{d^{2}}\right)}{\text { D. } \mathrm{h}_{\mathrm{b}}} \\
& \leq t \leq \frac{\mathrm{A}_{\mathrm{m}}}{h_{m}}\left(\frac{1}{\mathrm{Q}^{\mathrm{d}}}-\frac{1}{\mathrm{Q}^{c o}}\right)
\end{aligned}
$$

\subsection{Profit sharing}

By applying credit option contract, buyer's order quantity increases from $Q^{d}$ to $Q^{c o}$ and vendor compensates buyer's additional cost. However there is also a surplus profit at the upstream side of the chain. Surplus profit at the vendor's side is maximum when $t=t_{\min }$, on the other hand when $t=t_{\text {man }}$ all the benefits are at the buyer side. $t_{\min }$ and $t_{\max }$ are two bounds of the feasible credit time. The additional profit gained after coordination is shared between two parties via credit time and according to bargaining power of each side. When credit time is $t_{\min }$ the supplier gains its maximum yearly net profit:

$Y N P_{\text {mmax }}=(P-c) D-\frac{D A_{m}}{Q^{c o}}-D t_{\min } h_{m}$

To share the profit between two parties, two steps must occur: firstly, determining the value of additional profit after coordination. Secondly, players must share the profit according to bargaining power of the players. 
$Y N P_{m \text { max }}^{c o}-Y N P_{m}$ is extra profit of vendor after coordination.

We assume that bargaining powers of two players are equal, so extra profit should be shared equally. if $\Delta t$ shows the extra credit period it is calculable as follow:

$$
\Delta t=\frac{D t_{\max } h_{m}-D t_{\min } h_{m}}{2 D h_{b}}
$$

where total credit time is:

$$
t=t_{\min }+\Delta t
$$

and both coordination is achieved and surplus profit is shared between parties.

Finally, after coordination, the yearly net profit of the vendor and the buyer is:

$$
\begin{aligned}
& Y N P_{b}^{c o}=(R-P) D-\left[\left(\frac{D \cdot A_{b}}{Q^{c o}}+\frac{1}{2 Q^{c o}} h_{b} \cdot\left(Q^{c o}-s^{c o}\right)^{2}+\frac{1}{2 Q^{c o}} \hat{\pi} s^{c o^{2}}\right)\right] \\
& \quad+D\left(t_{\min }+\Delta t\right) h_{b} \\
& Y N P_{m}^{c o}=(P-c) D-\frac{D A_{m}}{Q^{c o}}-D\left(h_{m} t_{\text {min }}+h_{b} \Delta t\right)
\end{aligned}
$$

In the proposed mechanism, the supplier and buyer are coordinated by determining credit option contract parameters. Buyer accepts proposed order quantity and optimum backordered demand in each period (Eq. (8) and Eq. (9)) and supplier offers a credit time (Eq. (16)) to encourage the buyer to cooperate in the contract. After coordination, yearly net profit of the members can be calculated by (Eq. (17) and Eq. (18))

\section{Numerical illustration}

To illustrate the performance and profitability of the presented model, numerical examples are provided. The model is examined with a wide range of Data representative of a wide range of Inventory system adopted from Sarmah et al. (2007). Consider the inventory model of a supply chain with abovementioned (2.1) assumption.

\section{Table 1}

Data set

\begin{tabular}{cccccc}
\hline$\hat{\pi}$ & $\mathrm{D}$ & $\mathrm{h}_{\mathrm{b}}$ & $\mathrm{h}_{\mathrm{m}}$ & $\mathrm{A}_{\mathrm{b}}$ & $\mathrm{A}_{\mathrm{m}}$ \\
\hline 40 & 200 & 4 & 0.5 & 20 & 175 \\
50 & 650 & 8 & 1 & 100 & 350 \\
60 & 1200 & 16 & 2 & 150 & 700 \\
\hline $\mathrm{R}=140, \quad \mathrm{P}=120, \quad \mathrm{C}=100$ & & & &
\end{tabular}

For all 2187 cases of the data set (Table 1), model is solved and achieving to coordination is tested. Only for 378 cases, solution is feasible. Some results are presented in the Table A-1 of Appendix. The most important point is that, in all solved problems channel coordination is achieved. Statistical analysis has been provided to illustrate model's performance in different Inventory systems. Median of increase in the buyer's yearly net profit $\left(r_{1}=\frac{Y N P_{b}^{c o}}{Y N P_{b}}\right)$ in data set is 1.065 , it means than after coordination at least for $50 \%$ of cases, buyer's profit is increased more than $6.5 \%$. Besides, the minimum amount of $r_{1}$ is 1.01 ; it is deducible that in the wide range of settings which had been 
studied, at least the increase of $10 \%$ in the profit for the buyer has been achieved. The median of increase in buyer's yearly net profit increase $\left(r_{2}=\frac{Y N P_{m}^{c o}}{Y N P_{m}}\right)$ is 1.07 ; it means that after coordination, at least for $50 \%$ of cases, buyers profit is increased more than 7\%. The increase in mean Profit for the vendor is $13 \%$.

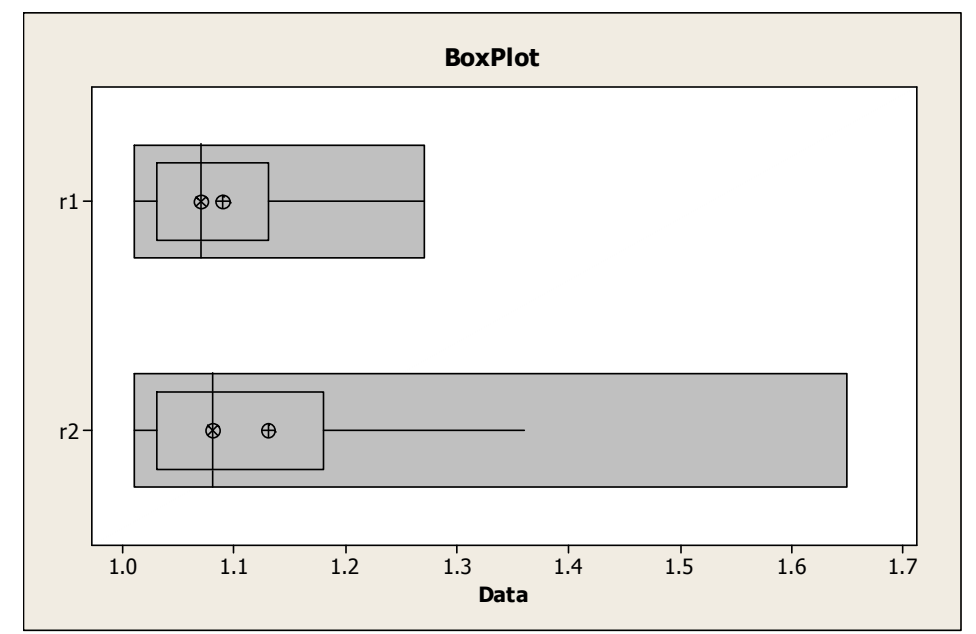

Fig. 1. BoxPlot for member`s increase in YNP after coordination

Fig. 1. Shows that:

- For our dataset, the range of $r_{2}$ is far greater than $r_{1}$. It means that after coordination the increase in supplier YNP is more sensitive to chain's parameters like holding and setup time than buyer.

- In the different inventory systems, both mean and median of increase in supplier's profit is greater than buyer's.

By considering aforementioned results, although coordination mechanism increases profit of two parties, the increase in vendor's profit is more than the buyer's and this is the core motive for the upstream member to propose a coordination contract. Consequently, the reason for considering the upstream member as a leader and proposer of a contract in almost all supply chains coordination game models is sensible.

According to Table 2, setting some parameters in special levels increases profit of both sides considerably. For an inventory system with $A_{m}=700$ (Maximum level in our data set), $A_{b}=100$ (Midlevel in our data set), $h_{b}=16$ (Maximum level in our data set) and $D=200$ (minimum level in our data set), the increase of buyer' profit $\left(r_{1}\right)$ is at least $24 \%$ (more than $Q_{3}$ ) and the increase of vendor's profit $\left(r_{2}\right)$ is at least $50 \%$ (more than $Q_{3}$ ). It means that not only proposed coordination mechanism increases members profit in all systems, but also it has significant effect on some special inventory systems.

According to numerical analysis it's obvious that mechanism's effect on different inventory systems is not the same, now the question is: "How the system parameters do effect on $r_{1}$ and $r_{2}$ ?". To answer this question a regression analysis was conducted on the above mentioned data set:

Response surface regression $r_{l} v s . A_{m}, A_{b}, h_{m}, h_{b}, D, \hat{\pi}$ and 
Response surface regression $r_{2}$ vs. $A_{m}, A_{b}, h_{m}, h_{b}, D, \hat{\pi}$. Table 3 Shows regression function coefficients.

Table 2

Regression analysis for $\mathrm{r}_{1}$ and $\mathrm{r}_{2}$

\begin{tabular}{llll}
\hline & $\mathrm{r}_{1}$ v.s Parameters & & \\
\hline Term & Coef. & Term & $\mathrm{r}_{2}$ v.s Parameters \\
\hline Constant & 0.9705 & Constant & 0.7795 \\
$\mathrm{Am}$ & 0.0002 & $\mathrm{Am}$ & 0.0001 \\
$\mathrm{Ab}$ & 0.0004 & $\mathrm{Ab}$ & 0.0037 \\
$\mathrm{hm}$ & -0.0031 & $\mathrm{hm}$ & -0.0032 \\
$\mathrm{hb}$ & 0.0047 & $\mathrm{hb}$ & 0.0085 \\
$\mathrm{D}$ & -0.0001 & $\mathrm{D}$ & -0.0004 \\
$\hat{\pi}$ & 0.0001 & $\hat{\pi}$ & -0.0001 \\
$\mathrm{hm} \times \mathrm{hb}$ & 0.0002 & $\mathrm{D} \times \mathrm{D}$ & 0.0097 \\
$\mathrm{hb} \times \mathrm{hb}$ & -0.0002 & --- & \\
\hline
\end{tabular}

Accordingly, $h_{m}$ and $h_{b}$ influence increase buyer's profit and $A_{m}, A_{b}, h_{b}$ influence on vendor's more than other parameters.

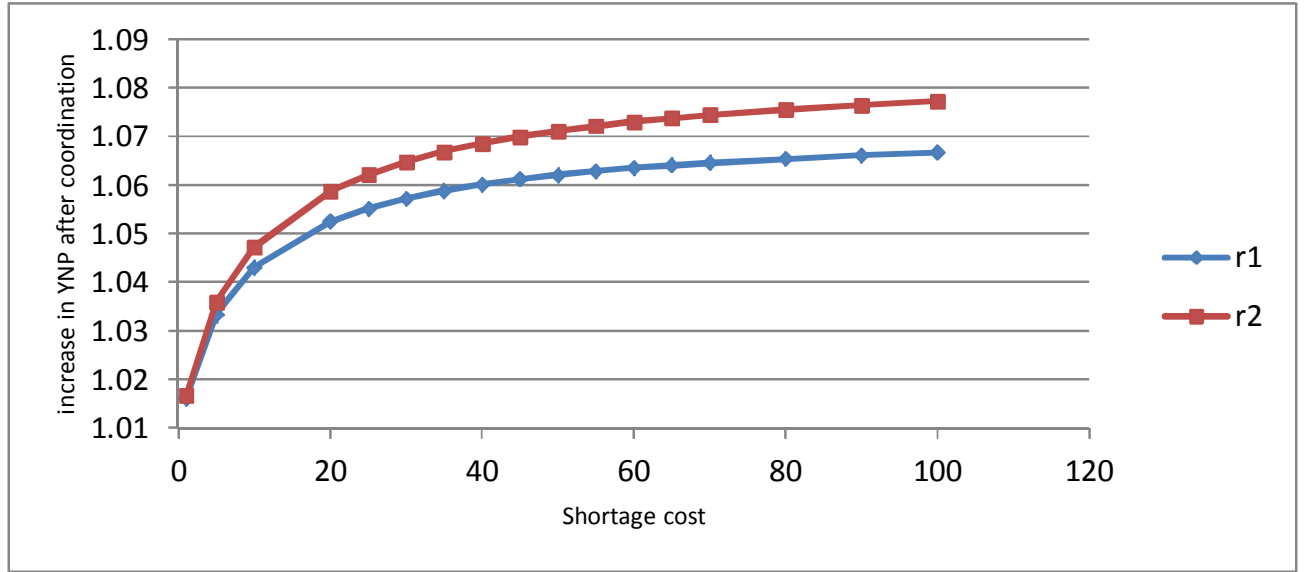

Fig. 2. Effect of shortage cost change

Fig. 2 demonstrates the effect of shortage cost change on increase in member's profit. The following statements are deducible from Fig. 2:

- Regardless to shortage cost, increase in supplier's profit is larger than the buyer.

- In enormous shortage costs, the described mechanism has better performance.

Fig. 3 illustrates the effect of shortage cost change on increase in member's profit after coordination.

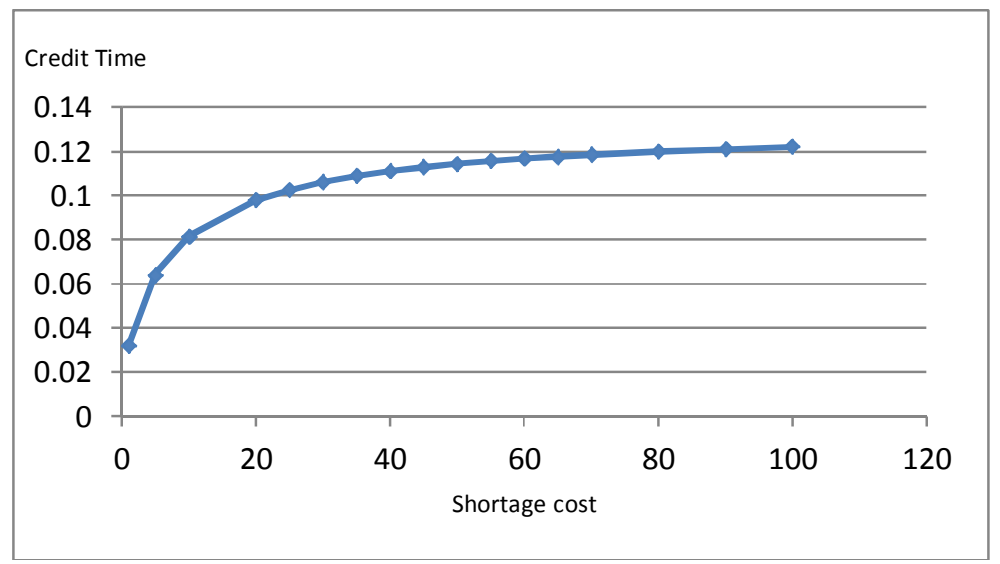

Fig. 3. Effect of Shortage cost on Credit time 
To investigate the effect of allowed shortage in coordination mechanism, we compare proposed credit time in two cases in the Fig. 4. When shortage is not allowed, credit time is a lower bound for the credit time when shortage is allowed. It means that, shortage allowance in an inventory system increases required credit time to coordinate the supplier and the buyer.

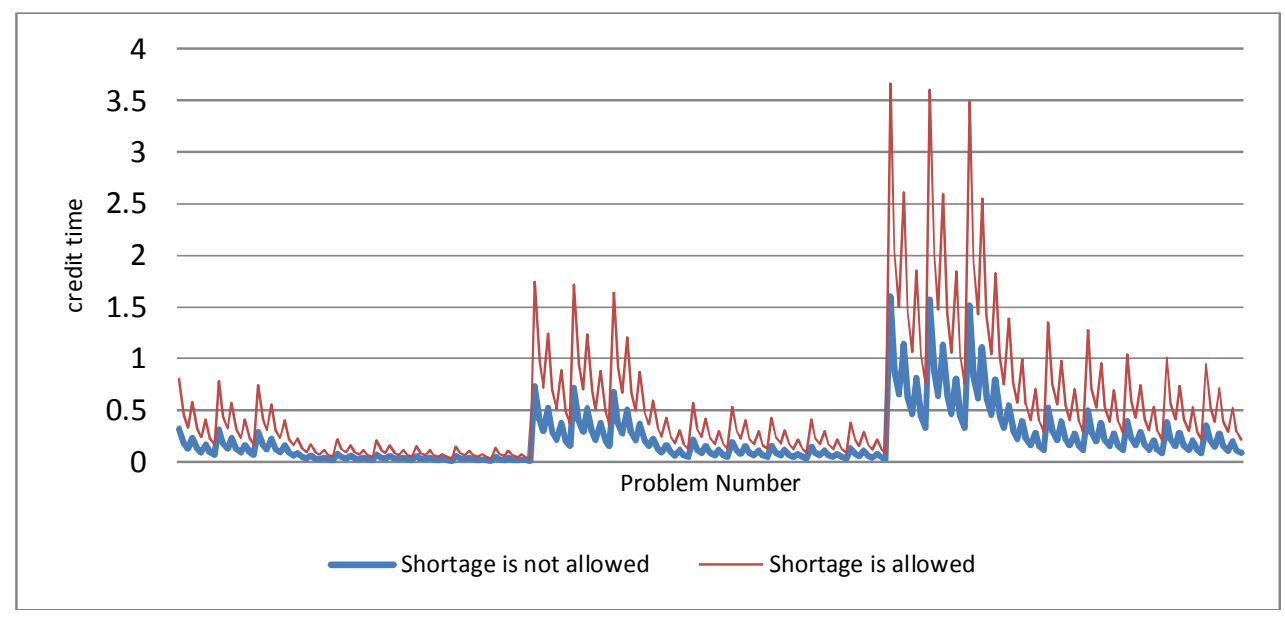

Fig. 4. Comapring credit time in allowance of shortage

\section{Conclusion}

In this paper, we have proposed a model to consider coordination of a supply chain with credit option contract. The common assumption in the literature was that shortage was not allowed in inventory systems. This assumption has been relaxed by assuming that backordered shortage is allowed and has been closed to realistic conditions. Optimum order size and backorder in the coordinated model have been calculated. The model was tested in wide range of inventory systems, in all test problems system we achieved channel coordination.

The proposed model is both desirable and efficient, because after coordination, member's $Y N P$ is equal or greater than their $Y N P$ before coordination and this encourage them to cooperate in the coordination mechanism, furthermore, chain's profit after coordination is equal to an equivalent centralized supply chain.

The following conclusions derived from the numerical results:

a) In a specific inventory system, although, after coordination, yearly net profit is increased for both sides of the chain, increase in vendor's profit is more than buyer's, accordingly, this is an incentive for vendor to propose a coordination contract

b) Some of the parameters have more effect on the increase in profit. After coordination $h_{m}, h_{b}$ affect buyer's and $A_{m}, A_{b}, h_{b}$ affect vendor's increase in profit more than other parameters.

\section{References}

Abad, P. L., \& Jaggi, C. K. (2003). A joint approach for setting unit price and the length of the credit period for a seller when end demand is price sensitive. International Journal of Production Economics, 83(2), 115-122.

Halati, A., \& He, Y. (2010). Analysis of supply chains with quantity based fixed incentives. European Journal of Operational Research, 202(1), 214-222.

Cachon, G. P. (2004). Supply Chain Coordination with Contracts. In Handbooks in Operations 
Research and Management Science (pp. 227-339). Philadelphia, PA 19104, USA: The Wharton School of Business $\varnothing$ University of Pennsylvania.

Cao To Linh, Y. H. (2009). Channel coordination through a revenue sharing contract in a two-period newsboy problem. European Journal of Operational Research, 198(3), 822-829.

Chaharsooghi, S. K., \& Heydari, J. (2010). Supply chain coordination for the joint determination of order quantity and reorder point using credit option. European Journal of Operational Research, 204(1), 86-95.

Ding, D., \& Chen, J. (2008). Coordinating a three level supply chain with flexible return policies. Omega, 36(5), 865-876.

Giannoccaro, I., \& Pontrandolfo, P. (2004). Supply chain coordination by revenue sharing contracts. International Journal of Production Economics, 89(2), 131-139.

Harris, F. (1913). How many parts to make at once. Operations Research (INFORMS), 38 (6), $947-$ 950.

Hill, R. O. (2006). Another look at the single-vendor single buyer integrated production-inventory problems. International Journal of Production Research, 44(4), 791-800.

Jaber, M. Y., \& Osman, I. H. (2006). Coordinating a two-level supply chain with delay in payments and profit sharing. Computers \& Industrial Engineering,50(4), 385-400.

Kanda, A., \& Deshmukh, S. G. (2008). Supply chain coordination: perspectives, empirical studies and research directions. International Journal of Production Economics, 115(2), 316-335.

Kanda, A., \& Deshmukh, S. G. (2009). A framework for evaluation of coordination by contracts: A case of two-level supply chains. Computers \& Industrial Engineering, 56(4), 1177-1191.

Kin Chan, C., Lee, Y. C. E., \& Goyal, S. K. (2010). A delayed payment method in co-ordinating a single-vendor multi-buyer supply chain. International Journal of Production Economics, 127(1), 95-102.

Lariviere, M. (2002). Inducing forecast revelation through restricted returns. EB/OL], Http://bctim. wust1. edu/calendar/mediafiles/Forecasts2002. pdf.

Li, S., \& Hua, Z. (2008). A note on channel performance under consignment contract with revenue sharing. European Journal of Operational Research,184(2), 793-796.

Malone, T. W., \& Crowston, K. (1994). The interdisciplinary study of coordination. ACM Computing Surveys (CSUR), 26(1), 87-119.

Pentico, D. W., \& Drake, M. J. (2011). A survey of deterministic models for the EOQ and EPQ with partial backordering. European Journal of Operational Research, 214(2), 179-198.

Sarmah, S. P., Acharya, D., \& Goyal, S. K. (2006). Buyer vendor coordination models in supply chain management. European journal of operational research, 175(1), 1-15.

Sarmah, S. P., Acharya, D., \& Goyal, S. K. (2007). Coordination and profit sharing between a manufacturer and a buyer with target profit under credit option. European Journal of Operational Research, 182(3), 1469-1478.

Sarmah, S. P., Acharya, D., \& Goyal, S. K. (2008). Coordination of a single-manufacturer/multibuyer supply chain with credit option. International Journal of Production Economics, 111(2), 676-685.

Sheen, G. J., \& Tsao, Y. C. (2007). Channel coordination, trade credit and quantity discounts for freight cost. Transportation Research Part E: Logistics and Transportation Review, 43(2), $112-$ 128.

Wang, Q. (2004). Coordinating independent buyers with integer-ratio time coordination and quantity discounts. Naval Research Logistics, 51(3), 316-331.

Zhou, Y.-W. (2009). Two-echelon supply chain coordination through the unified number of annual orders. International Journal of Production Economics, 117(1), 162-173. 


\section{Appendix A}

Table A-1

Calculation results for some problems of dataset

\begin{tabular}{|c|c|c|c|c|c|c|c|c|c|c|c|c|c|c|c|c|c|c|}
\hline No & $\mathbf{A}_{\mathrm{m}}$ & $\mathbf{A}_{\mathbf{b}}$ & $\mathbf{h}_{\mathrm{m}}$ & $\mathbf{h}_{\mathrm{b}}$ & D & $\pi$ & $\hat{\pi}$ & $\mathbf{Q}_{\text {op }}$ & $S_{\text {op }}$ & $\mathbf{Y N P}_{\mathbf{b}}$ & $\mathbf{Y N P}_{\mathrm{m}}$ & $Q^{\text {co }}$ & $\mathbf{S}^{\mathrm{co}}$ & $\mathbf{Y N P}_{\mathbf{b}}{ }^{\mathrm{co}}$ & $\mathrm{YNP}_{\mathrm{m}}{ }^{\mathrm{co}}$ & r1 & r2 & $\mathbf{t}$ \\
\hline 1 & 175 & 100 & 1 & 8 & 200 & 2 & 40 & 74 & 4 & 3439 & 3528 & 126 & 13 & 3534 & 3623 & 1.03 & 1.03 & 0.10 \\
\hline 2 & 175 & 100 & 1 & 8 & 200 & 2 & 50 & 73 & 3 & 3438 & 3524 & 125 & 10 & 3534 & 3619 & 1.03 & 1.03 & 0.11 \\
\hline 3 & 175 & 100 & 1 & 8 & 200 & 2 & 60 & 73 & 3 & 3437 & 3521 & 123 & 9 & 3531 & 3614 & 1.03 & 1.03 & 0.10 \\
\hline 4 & 175 & 100 & 1 & 16 & 200 & 2 & 40 & 57 & 9 & 3234 & 3386 & 97 & 21 & 3357 & 3509 & 1.04 & 1.04 & 0.07 \\
\hline 5 & 175 & 100 & 1 & 16 & 200 & 2 & 50 & 56 & 7 & 3228 & 3371 & 94 & 17 & 3354 & 3497 & 1.04 & 1.04 & 0.07 \\
\hline 6 & 175 & 100 & 1 & 16 & 650 & 2 & 50 & 93 & 3 & 11560 & 11774 & 165 & 20 & 11823 & 12037 & 1.02 & 1.02 & 0.04 \\
\hline 7 & 175 & 100 & 1 & 16 & 650 & 2 & 60 & 92 & 2 & 11560 & 11768 & 163 & 17 & 11820 & 12029 & 1.02 & 1.02 & 0.04 \\
\hline 8 & 175 & 100 & 2 & 8 & 200 & 2 & 40 & 74 & 4 & 3439 & 3528 & 126 & 13 & 3528 & 3617 & 1.03 & 1.03 & 0.10 \\
\hline 9 & 350 & 150 & 2 & 4 & 200 & 2 & 50 & 124 & 2 & 3511 & 3436 & 231 & 10 & 3618 & 3543 & 1.03 & 1.03 & 0.25 \\
\hline 10 & 350 & 150 & 2 & 4 & 200 & 2 & 60 & 124 & 1 & 3511 & 3435 & 229 & 8 & 3618 & 3542 & 1.03 & 1.03 & 0.25 \\
\hline 11 & 350 & 150 & 2 & 8 & 200 & 2 & 40 & 92 & 7 & 3319 & 3241 & 172 & 20 & 3479 & 3401 & 1.05 & 1.05 & 0.18 \\
\hline 12 & 350 & 150 & 2 & 16 & 650 & 2 & 50 & 118 & 9 & 11252 & 11076 & 227 & 35 & 11693 & 11517 & 1.04 & 1.04 & 0.07 \\
\hline 13 & 350 & 150 & 2 & 16 & 650 & 2 & 60 & 117 & 8 & 11249 & 11055 & 223 & 30 & 11692 & 11497 & 1.04 & 1.04 & 0.07 \\
\hline 14 & 700 & 100 & 1 & 8 & 200 & 2 & 40 & 74 & 4 & 3439 & 2112 & 218 & 28 & 4052 & 2725 & 1.18 & 1.29 & 0.58 \\
\hline 15 & 700 & 100 & 1 & 8 & 200 & 2 & 50 & 73 & 3 & 3438 & 2095 & 214 & 23 & 4054 & 2711 & 1.18 & 1.29 & 0.58 \\
\hline 16 & 700 & 100 & 1 & 8 & 200 & 2 & 60 & 73 & 3 & 3437 & 2083 & 212 & 19 & 4056 & 2701 & 1.18 & 1.30 & 0.59 \\
\hline 17 & 700 & 100 & 1 & 8 & 200 & 2 & 60 & 73 & 3 & 3437 & 2083 & 212 & 19 & 4046 & 2691 & 1.18 & 1.29 & 0.58 \\
\hline 18 & 700 & 100 & 1 & 16 & 200 & 2 & 40 & 57 & 9 & 3234 & 1544 & 167 & 40 & 4029 & 2339 & 1.25 & 1.51 & 0.38 \\
\hline 19 & 700 & 150 & 1 & 16 & 650 & 2 & 40 & 120 & 11 & 11256 & 9211 & 307 & 64 & 12399 & 10354 & 1.10 & 1.12 & 0.17 \\
\hline 20 & 700 & 150 & 1 & 16 & 650 & 2 & 50 & 118 & 9 & 11252 & 9151 & 298 & 53 & 12404 & 10303 & 1.10 & 1.13 & 0.17 \\
\hline 21 & 700 & 150 & 1 & 16 & 650 & 2 & 60 & 117 & 8 & 11249 & 9109 & 293 & 45 & 12407 & 10267 & 1.10 & 1.13 & 0.18 \\
\hline 22 & 700 & 150 & 1 & 4 & 200 & 2 & 40 & 124 & 2 & 3511 & 2875 & 304 & 19 & 3819 & 3183 & 1.09 & 1.11 & 0.63 \\
\hline 23 & 700 & 150 & 1 & 4 & 200 & 2 & 50 & 124 & 2 & 3511 & 2872 & 302 & 15 & 3819 & 3180 & 1.09 & 1.11 & 0.63 \\
\hline 24 & 700 & 150 & 1 & 4 & 200 & 2 & 60 & 124 & 1 & 3511 & 2869 & 300 & 13 & 3818 & 3177 & 1.09 & 1.11 & 0.63 \\
\hline 25 & 700 & 150 & 1 & 8 & 200 & 2 & 40 & 92 & 7 & 3319 & 2481 & 225 & 29 & 3750 & 2913 & 1.13 & 1.17 & 0.43 \\
\hline 26 & 700 & 150 & 1 & 8 & 200 & 2 & 50 & 91 & 6 & 3317 & 2463 & 221 & 24 & 3752 & 2899 & 1.13 & 1.18 & 0.44 \\
\hline
\end{tabular}

Table A-2

Calculation results for some problems of dataset

\begin{tabular}{|c|c|c|c|c|c|c|c|c|c|c|c|c|c|c|c|c|c|c|}
\hline No & $\mathbf{A}_{\mathbf{m}}$ & $\mathbf{A}_{\mathrm{b}}$ & $\mathbf{h}_{\mathrm{m}}$ & $\mathbf{h}_{b}$ & D & $\pi$ & $\hat{\pi}$ & $\mathbf{Q}_{\text {op }}$ & $S_{\text {op }}$ & $\mathbf{Y N P}_{\mathrm{b}}$ & $\mathbf{Y N P}_{\mathrm{m}}$ & $Q^{\text {co }}$ & $\mathrm{S}^{\mathrm{co}}$ & $\mathbf{Y N P}_{\mathrm{b}}{ }^{\mathrm{co}}$ & $\mathrm{YNP}_{\mathrm{m}}{ }^{\mathrm{co}}$ & r1 & r2 & $t$ \\
\hline 1 & 175 & 100 & 1 & 8 & 200 & 2 & 40 & 74 & 4 & 3439 & 3528 & 126 & 13 & 3534 & 3623 & 1.03 & 1.03 & 0.10 \\
\hline 2 & 175 & 100 & 1 & 8 & 200 & 2 & 50 & 73 & 3 & 3438 & 3524 & 125 & 10 & 3534 & 3619 & 1.03 & 1.03 & 0.11 \\
\hline 3 & 175 & 100 & 1 & 8 & 200 & 2 & 60 & 73 & 3 & 3437 & 3521 & 123 & 9 & 3531 & 3614 & 1.03 & 1.03 & 0.10 \\
\hline 4 & 175 & 100 & 1 & 16 & 200 & 2 & 40 & 57 & 9 & 3234 & 3386 & 97 & 21 & 3357 & 3509 & 1.04 & 1.04 & 0.07 \\
\hline 5 & 175 & 100 & 1 & 16 & 200 & 2 & 50 & 56 & 7 & 3228 & 3371 & 94 & 17 & 3354 & 3497 & 1.04 & 1.04 & 0.07 \\
\hline 6 & 175 & 100 & 1 & 16 & 650 & 2 & 50 & 93 & 3 & 11560 & 11774 & 165 & 20 & 11823 & 12037 & 1.02 & 1.02 & 0.04 \\
\hline 7 & 175 & 100 & 1 & 16 & 650 & 2 & 60 & 92 & 2 & 11560 & 11768 & 163 & 17 & 11820 & 12029 & 1.02 & 1.02 & 0.04 \\
\hline 8 & 175 & 100 & 2 & 8 & 200 & 2 & 40 & 74 & 4 & 3439 & 3528 & 126 & 13 & 3528 & 3617 & 1.03 & 1.03 & 0.10 \\
\hline 9 & 350 & 150 & 2 & 4 & 200 & 2 & 50 & 124 & 2 & 3511 & 3436 & 231 & 10 & 3618 & 3543 & 1.03 & 1.03 & 0.25 \\
\hline 10 & 350 & 150 & 2 & 4 & 200 & 2 & 60 & 124 & 1 & 3511 & 3435 & 229 & 8 & 3618 & 3542 & 1.03 & 1.03 & 0.25 \\
\hline 11 & 350 & 150 & 2 & 8 & 200 & 2 & 40 & 92 & 7 & 3319 & 3241 & 172 & 20 & 3479 & 3401 & 1.05 & 1.05 & 0.18 \\
\hline 12 & 350 & 150 & 2 & 16 & 650 & 2 & 50 & 118 & 9 & 11252 & 11076 & 227 & 35 & 11693 & 11517 & 1.04 & 1.04 & 0.07 \\
\hline 13 & 350 & 150 & 2 & 16 & 650 & 2 & 60 & 117 & 8 & 11249 & 11055 & 223 & 30 & 11692 & 11497 & 1.04 & 1.04 & 0.07 \\
\hline 14 & 700 & 100 & 1 & 8 & 200 & 2 & 40 & 74 & 4 & 3439 & 2112 & 218 & 28 & 4052 & 2725 & 1.18 & 1.29 & 0.58 \\
\hline 15 & 700 & 100 & 1 & 8 & 200 & 2 & 50 & 73 & 3 & 3438 & 2095 & 214 & 23 & 4054 & 2711 & 1.18 & 1.29 & 0.58 \\
\hline 16 & 700 & 100 & 1 & 8 & 200 & 2 & 60 & 73 & 3 & 3437 & 2083 & 212 & 19 & 4056 & 2701 & 1.18 & 1.30 & 0.59 \\
\hline 17 & 700 & 100 & 1 & 8 & 200 & 2 & 60 & 73 & 3 & 3437 & 2083 & 212 & 19 & 4046 & 2691 & 1.18 & 1.29 & 0.58 \\
\hline 18 & 700 & 100 & 1 & 16 & 200 & 2 & 40 & 57 & 9 & 3234 & 1544 & 167 & 40 & 4029 & 2339 & 1.25 & 1.51 & 0.38 \\
\hline 19 & 700 & 150 & 1 & 16 & 650 & 2 & 40 & 120 & 11 & 11256 & 9211 & 307 & 64 & 12399 & 10354 & 1.10 & 1.12 & 0.17 \\
\hline 20 & 700 & 150 & 1 & 16 & 650 & 2 & 50 & 118 & 9 & 11252 & 9151 & 298 & 53 & 12404 & 10303 & 1.10 & 1.13 & 0.17 \\
\hline 21 & 700 & 150 & 1 & 16 & 650 & 2 & 60 & 117 & 8 & 11249 & 9109 & 293 & 45 & 12407 & 10267 & 1.10 & 1.13 & 0.18 \\
\hline 22 & 700 & 150 & 1 & 4 & 200 & 2 & 40 & 124 & 2 & 3511 & 2875 & 304 & 19 & 3819 & 3183 & 1.09 & 1.11 & 0.63 \\
\hline 23 & 700 & 150 & 1 & 4 & 200 & 2 & 50 & 124 & 2 & 3511 & 2872 & 302 & 15 & 3819 & 3180 & 1.09 & 1.11 & 0.63 \\
\hline 24 & 700 & 150 & 1 & 4 & 200 & 2 & 60 & 124 & 1 & 3511 & 2869 & 300 & 13 & 3818 & 3177 & 1.09 & 1.11 & 0.63 \\
\hline 25 & 700 & 150 & 1 & 8 & 200 & 2 & 40 & 92 & 7 & 3319 & 2481 & 225 & 29 & 3750 & 2913 & 1.13 & 1.17 & 0.43 \\
\hline 26 & 700 & 150 & 1 & 8 & 200 & 2 & 50 & 91 & 6 & 3317 & 2463 & 221 & 24 & 3752 & 2899 & 1.13 & 1.18 & 0.44 \\
\hline
\end{tabular}

